\title{
POLÍTICA PÚBLICA EDUCATIVA PROEJA: ENTRE O PLANO DOS DISCURSOS E O PLANO DA AÇÃO NO CONTEXTO DO NEOLIBERALISMO
}

\author{
T. M. D. FLORES \\ Instituto Federa de Educação, Ciência e Tecnologia da Bahia \\ ORCID ID: http://orcid.org/0000-0001-7580-6234 \\ taniaflores@ifba.edu.br
}

Submetido 26/06/2020 - Aceito 30/09/2020

DOI: $10.15628 /$ holos. 2020.10597

\section{RESUMO}

O alinhamento entre o plano dos discursos e o plano da ação, especialmente no contexto do neoliberalismo e da pósdemocracia, pode apresentar vários problemas, como o modelo de gestão sem a participação do povo; sem política, porém, com estratégias que acomodem os conflitos e deem ao povo a ilusão de democracia. Tal desalinhamento materializa- se, por exemplo, no modo de execução de políticas públicas sociais e educativas que as distancia dos objetivos propostos a nível dos discursos político-normativos. O presente artigo consiste numa metanálise da política pública brasileira 'Programa de Integração da Educação Básica à Educação Profissional na modalidade de Educação de Jovens e Adultos - PROEJA" destinada aos jovens e adultos que foram excluídos do direito à educação formal em idade estabelecida por lei, cujo objetivo central é, Segundo o discurso político, elevar a escolaridade dessa parcela da população e, sobretudo, possibilitar-lhe qualificação professional para incluí-la, também, no mundo do trabalho e no efetivo exercício da cidadania. 0 objetivo desta pesquisa é avaliar em que medida os discursos politiconormativos para a inclusão se materializam no Plano da ação. Assim, para composição do corpus empírico, selecionaram-se, no banco de teses da CAPES, dez investigações realizadas por investigadores brasileiros sobre a execução da política, todas no contexto do Estado da Bahia, no período de 2010 a 2017. Para o presente artigo, elegeu-se, a categoria de análise 'acesso", primeiro passo para a inclusão proposta pela política. As principais referências teóricas (Ranciére, 1999, 2014; Pinto, 2017; Crouch, 2000, 2004) possibilitaram perceber as razões do desalinhamento entre aquilo que é propagado e aquilo que efetivamente ocorre. Assegurar o acesso do público-alvo é um importante passo na operacionalização do plano de ação da política. Todavia, o corpus empírico analisado deixou evidente que, majoritariamente, os estudantes que ingressaram no PROEJA não são do público especificado pela política, o que caracteriza grande abismo entre os discursos e a ação

PALAVRAS-CHAVE: PROEJA, pós-democracia, discursos político-normativos, plano da ação, exclusão/inclusão.

\section{PROEJA PUBLIC EDUCATIONAL POLICY: BETWEEN THE SPEECH PLAN AND THE PLAN OF ACTION IN THE CONTEXT OF NEOLIBERALISM}

\section{ABSTRACT}

In the context of neoliberalism and post-democracy, the alignment between the discourse plan and the action plan can present several problems, such as the management model without participation of the people; without policies, however, with strategies that accommodate conflicts and give the people the illusion of democracy. Such misalignment materializes, for example, in the way of executing public social and educational policies distancing them from the proposed goals to a level of political-normative discourses. This article consists of a metaanalysis of the Brazilian public policy Program for the Integration of Basic Education for Professional Education in the Youth and Adult Education modality - PROEJA' - aimed at young people and adults who were excluded from the right to formal education at an age established by law, in this central objective it is, according to the political discourse, to raise the education level of this part of the population and, mainly, to make possible the professional qualification and finally include them, in the work world and in the effective conscious exercise of citizenship. Thus, for the composition of the empirical body, were selected, on CAPES thesis bank, ten investigations carried out by Brazilian researchers on policy implementation, all in the context of the State of Bahia, at the period from 2010 to 2017 For the present article, the analysis category chosen was "access", the first step towards the inclusion proposed by the policy. The main theoretical references maked possible perceiving the misalignment's reasons between what is propagated and which is effectively occurs. To guarantee the access to the peaple that are aimed by the policy, is an important step in operationalizing the policy's action plan. However, the empirical corpus analyzed made it evident that mainly, the students who joined PROEJA are not the profile specified by the policy, which characterize the great gap between discourses and actions.

KEYWORDS: PROEJA, post-democracy, political-normative, discourses, plan of action, exclusion/inclusion. 


\section{APRESENTAÇÃO}

O Programa Nacional de Integração da Educação Profissional com a Educação Básica na Modalidade de Educação de Jovens e Adultos - PROEJA - é uma política educativa de cariz afirmativo, cujo principal objetivo é, através da educação básica, integrada à educação profissional, incluir, no sistema educativo, jovens e adultos que não concluíram a educação básica em idade estabelecida por lei para incluí-los, também, no mundo do trabalho. 0 presente artigo apresenta uma metanálise sobre a execução dessa política, relacionando os resultados detectados nas investigações científicas que compõem o corpus empírico deste trabalho com o debate recente sobre pós-democracia e sua relação com o enfraquecimento da democracia, que ocorre democraticamente, escamoteando o fato de que, muito mais do que a participação democrática, o atual contexto, baseado numa nova etapa do neoliberalismo, está focado na manutenção dos interesses econômicos em detrimentos dos interesses sociais, nomeadamente, aqui, do direito fundamental à educação.

A análise realizada neste artigo limita-se à categoria acesso, mas considera as condições de implementação, importante etapa de qualquer política, especialmente educativa, que pode favorecer ou não o acesso do público ao qual ela se destina, visto que, para além do acesso, a inclusão já se desenha no seu processo de implementação a partir dos discursos políticonormativos presentes na sua formulação e regulamentação. Verifica-se, portanto, nas dez investigações realizadas no Estado da Bahia (Brasil), como se dá o acesso ao PROEJA, quem consegue ser beneficiado e, principalmente, qual o público que tem acessado o programa.

Neste artigo buscou-se apresentar como as condições de acesso, seja no processo seletivo, na divulgação das vagas ou mesmo nas divergências entre discurso e ação do estado e das instituições de ensino, por si só, já comprometem o resultado da política e, com isso, o PROEJA segue, no plano da ação, reproduzindo as desigualdades e exclusões que, segundo o plano do discurso normativo, a política foi supostamente projetada para combater.

Embora seja regra a dificuldade de atender ao público-alvo da política, a detecção de investigação que aponta no caminho inverso, de fortalecimento e ampliação do acesso ao público da EJA, demonstram que a falha não está em como a política foi pensada, mas em como ela tem sido implementada. Logo o plano da ação e o plano do discurso, estando alinhados, levam a resultados positivos e muito mais satisfatórios, como veremos adiante. Todavia, a falta de um processo de monitoramento das ações do PROEJA por parte do Ministério da Educação para garantir a plena execução do Programa se caracteriza numa omissão consciente, permitindo que os números de concluintes do PROEJA sejam apresentados como uma vitória para a inclusão no país, quando, na verdade, mascara o fato de que a maioria dos estudantes que ingressam no programa não são o público-alvo da política. 


\section{CONTEXTO DO NEOLIBERALISMO E DA PÓS-DEMOCRACIA: PLANO DO DISCURSO VS. PLANO DA AÇÃO}

Pós-democracia, termo cunhado por Ranciére, é, segundo o próprio autor, $(1999, p$. 27) "Uma distribuição específica do sensível que sintetiza formas de rejeição (recusa) sob a bandeira do consenso". Também Colin Crouch (2004) afirma que a pós-democracia consiste num regime em que os interesses do mercado se sobrepõem ao bem-estar social (Estadoprovidência), no qual predomina a ideia do estado mínimo, mecanismo para assegurar a centralidade do mercado (Estado neoliberal). Em termos mais específicos, Ranciére (2014) conceitua como pós-democrático o regime que, em seu modus operandi, demonstra querer "governar sem o povo, isto é, sem participação e sem divisão do povo; governar sem política" (Ranciére, 2014, p.102). Para ambos os autores, esse regime possui instituições democráticas formais, entretanto, escamoteiam seus objetivos de promover a desmobilização política para esvaziamento dos espaços políticos, muitas vezes, através de implantação de políticas, pretensamente inclusivas, cujo objetivo maior é a simulação de atendimento das reivindicações sociais para calar o clamor da sociedade e acomodar os conflitos.

Para Arendt (1993), a ação e o discurso são mecanismos capazes de criar o espaço político (der politik). Na concepção da autora, ele, além de dar visibilidade ao homem, garante-lhe poder efetivo na sua atuação, em cuja cena os pactos e acordos são firmados independentemente de parâmetros universais de legitimidade. Compreende-se esse espaço, portanto, como o lugar onde os sujeitos expressam, projetam e discutem, entre pares, suas pautas, necessidades e interesses, reivindicam direitos e atendimento das suas demandas e efetiva participação nas decisões políticas. Healey (2006) chama a atenção no sentido de que o espaço de participação deve ser, simultaneamente, espaço político e de formação política. É, portanto, no espaço político, no exercício da política e da cidadania, nas discussões e embates travados no espaço político que a formação política se forja.

Os discursos político-normativos, em sociedades pós-democráticas, são tecidos para veicular e convencer a sociedade de que o governo está em ação na defesa dos interesses do povo. Incluir uma pauta de grupos sociais na agenda política, criar políticas públicas para a inclusão dos 'marginalizados'pode signiificar muito mais um meio de manter, como destaca Ranciére (2014), a "parte que não faz parte" à margem, porém, com encenação de democracia para desmobilização do espaço político, por meio da utopia do consenso, como máscara para os dissensos, e da inclusão pensada e formatada não para combater a exclusão, mas, para ocultála. Desse modo, o poder político transforma o espaço político num espaço ausente, justamente para que a formação política não se concretize.

Uma análise entre o plano do discurso (o que é proposto e prometido) e o plano da ação (o quê e como, de fato, a proposta é executada ) pode ser bastante reveladora de estratégias adotadas pelas oligarquias para a manutenção do status quo. Nesse sentido, Ranciére (2004) ressalta que, não obstante uma sociedade adotar regras mínimas para ser considerada democrática - sistema representativo, mandatos eletivos, proposição e votação de leis, políticas, etc - na prática, no plano da ação, essas regras servem essencialmente para garantir o governo àqueles que almejam 
o poder pelo poder. Embora a aparência seja de democracia, trata-se de estados oligárquicos, cujo modus operandi é dar "à minoria mais forte o poder de governar sem distúrbios e criar uma maioria e uma oposição que estão de acordo com as políticas a ser praticadas" (Ranciére, 2004, p.97).

Uma das graves consequências desse processo, segundo Crouch (2000) "é a crescente impotência de causas igualitárias." (CROUCH, 2000, p. 137). Nesse sentido, notadamente no Brasil, a causa da educação é, provavelmente, a que se desdobra em diversas outras consequências que se traduzem em negação de direitos do cidadão, assegurados pela Constituição brasileira. Mas, também aqui, deve-se considerar que a legislação é um discurso do vir-a-ser, é o 'ideal' pensado pelos legisladores. Contudo, entre o 'ideal' e o 'real' situa-se o abismo da ação. A transposição das leis democráticas para a práxis, para a vida social, somente pode ser exequível num sistema efetivamente democrático, em que é dever do estado prover e assegurar, primordialmente, o bem- estar social, princípio corrompido pelo neoliberalismo e pela pósdemocracia, que deslocaram os interesses para o atendimento das demandas do mercado.

Nesse sentido, as políticas públicas, no plano da ação, apesar dos discursos supostamente democráticos, efetivamente priorizam o monetário em detrimento do social. Veremos adiante como a análise e avaliação da política pública PROEJA - quanto aos discursos e à ação, ratifica o que afirmam os teóricos da pós-democracia.

\section{METODOLOGIA}

Este artigo é parte de uma investigação mais ampla, que se insere no paradigma interpretativo, de natureza predominantemente qualitativa (Coutinho, 2016; Bogdan \& Biklen, 1994; Bryman, 2012), do Programa Doutoral em Educação da Universidade de Aveiro, Portugal, cujo objeto de estudo é a política pública PROEJA no Estado da Bahia, Brasil, no período entre 2009 a 2017, com o objetivo de avaliar o impacto da sua execução no tocante à efetiva inclusão - ou não dos sujeitos da Educação de Jovens e Adultos - EJA - no sistema educativo, para elevação da escolaridade e profissionalização, conforme veiculam os discursos político-normativos.

A partir da premissa de que, em sistemas políticos pós-democráticos, políticas públicas especialmente as que se destinam às classes populares - podem ser muito mais um simulacro de democracia do que vontade política de atender demandas de grupos sociais organizados que produzem debates (barulho incômodo) no espaço político, conforme afirmam Ranciére (2014) e Crouch (2004), optou-se por analisar o plano da ação da política, ou seja, sua efetiva execução, a fim de compreender sintonias ou dissonâncias entre os planos do discurso e da ação.

Adotou-se, assim, a metanálise qualitativa (Pinto 2013; Zimmer 2006; Finfgeld 2003), justamente por este método de pesquisa possibilitar a consociação de estudos primários sobre a política pública PROEJA para se obter uma síntese de cunho científico sobre a execução dessa política educacional, de relevante importância social, pelo seu caráter inclusivo, compensatório, e, sobretudo, emancipatório. Vale ressaltar que Cardoso (2007) destaca a evolução da metanálise de uma perspectiva homogeneamente quantitativa a uma perspectiva qualitativa e acrescenta que 0 incremento de dados qualitativos quanto à utilização da metanálise possibilita alcançar uma síntese interpretativa dos dados, ainda que técnicas quantitativas estejam presentes em alguns estudos. 
Nesse sentido, Pinto (2013) $)^{1}$, apresenta detalhada evolução histórica da metanálise, destacando sua aplicação nas ciências humanas. Também Zimmer(2006) adota o termo metassíntese como equivalente a meta-pesquisa ou metanálise qualitativa e análise agregadora.

Realizou-se pesquisa no banco de teses e dissertações da Coordenação de Aperfeiçoamento de Pessoal de Nível Superior - CAPES - a partir dos recortes temporal - 2010 a 2017 - e espacial Estado da Bahia, e dos descritores "PROEJA, Educação profissional, implementação e acesso", foram catalogados 21 estudos cujo contexto de pesquisa foi o Estado da Bahia. Entretanto, ao refinar a pesquisa através da nuvem de palavras utilizadas como critérios de inclusão, inferidas a partir dos conceitos estruturantes dos objetivos e orientações do DB da política e dos demais documentos que a regulamentam (inclusão, formação de professores, mundo do trabalho, permanência, conclusão) restaram 10 estudos que compõem o corpus empírico para a metanálise, conforme Tabela 02 apresentada no capítulo Metodologia.

Adotar a metanálise qualitativa, tendo como corpus investigações realizadas por investigadores brasileiros na área de Educação, sobre a política pública PROEJA na Bahia, permite ao investigador "reunir todo o relevante conteúdo disponível sobre determinada temática a fim de ajudar a compreender os fenômenos e ampliar o conhecimento" (Lopes, Fracolli, 2008, p. 775). Assim, o processo de descrição interpretativa forneceu um amplo panorama sobre as discrepâncias e incongruências entre os discursos político-normativos presentes no Documento Base (DB) da política e demais ordenamentos jurídicos legais que a regulamentam, e a sua concreta execução, sua materialidade no plano da ação.

Logo, os dez trabalhos selecionados ofereceram condições para compreender o plano da ação da política, a partir da categoria de análise "acesso", primeiro e fundamental passo para que o processo inicial de inclusão, de fato, para além do plano dos discursos, se consubstancie concretamente na vida dos excluídos.

\footnotetext{
${ }^{1}$ Para maiores informações, consultar: PINTO, Candida. Metanálise Qualitativa como Abordagem Metodológica para Pesquisas em Letras.http://proxy.furb.br/ojs/index.php/atosdepesquisa/article/view/4023/2491
} 
Tabela 1: Corpus empírico da investigação

\begin{tabular}{|c|c|c|c|c|c|}
\hline ESTUDO & ANO & AUTOR(A) & TíTULO & CONTEXTO & FRASE ILUSTRATIVA \\
\hline E01 & 2010 & $\begin{array}{l}\text { LIMA, } \\
\text { Jacilene } \\
\text { Fiúza de }\end{array}$ & $\begin{array}{l}\text { O PROEJA, seus beneficiários e as } \\
\text { baixas taxas de conclusão em um } \\
\text { dos cursos do Programa }\end{array}$ & $\begin{array}{l}\text { IFBA - } \\
\text { Salvador }\end{array}$ & $\begin{array}{l}\text { O PROEJA no IFBA tem um público } \\
\text { composto por uma maioria de } \\
\text { alunos com ensino médio } \\
\text { concluído. }\end{array}$ \\
\hline $\mathrm{E} 02 * *$ & 2011 & $\begin{array}{c}\text { ALMEIDA, } \\
\text { Márcia } \\
\text { Simões de }\end{array}$ & $\begin{array}{c}\text { "Da formação do sujeito ao } \\
\text { sujeito da formação": saberes e } \\
\text { experiências dos jovens e adultos } \\
\text { do PROEJA }\end{array}$ & $\begin{array}{l}\text { IFBA - } \\
\text { Salvador }\end{array}$ & $\begin{array}{l}\text { A EJA tem suas especificidades e os } \\
\text { docentes não foram preparados } \\
\text { para tal, embora o perfil do público } \\
\text { atendido praticamente não seja da } \\
\text { EJA. }\end{array}$ \\
\hline E03 & 2011 & $\begin{array}{c}\text { FERNANDE } \\
\text { S, Marta } \\
\text { Quadros }\end{array}$ & $\begin{array}{c}\text { O Instituto Federal de Educação, } \\
\text { Ciência e Tecnologia da Bahia e o } \\
\text { PROEJA: O caso do Campus de } \\
\text { Vitória da Conquista }\end{array}$ & $\begin{array}{c}\text { IFBA - Vitória } \\
\text { da } \\
\text { Comquista }\end{array}$ & $\begin{array}{l}\text { A presença de egressos do EM no } \\
\text { PROEJA sugere carência de } \\
\text { divulgação dos cursos por parte } \\
\text { dos Institutos Federais }\end{array}$ \\
\hline E04 & 2012 & \begin{tabular}{|c|} 
BONFIM, \\
Silvana V. \\
M. da Silva.
\end{tabular} & $\begin{array}{c}\text { A problemática da evasão dos } \\
\text { estudantes vinculados ao PROEJA } \\
\text { no IF BAIANO - Campus } \\
\text { Guanambi }\end{array}$ & $\begin{array}{l}\text { IFBAIANO- } \\
\text { Guanambi }\end{array}$ & $\begin{array}{c}\text { O curso téc. em informática } \\
\text { implantado para atender aos } \\
\text { interesses do próprio Campus, não } \\
\text { às expectativas do público alvo }\end{array}$ \\
\hline E05 & 2014 & \begin{tabular}{|} 
OLIVEIRA, \\
Maria da C. \\
da V.P. de
\end{tabular} & $\begin{array}{l}\text { O curso Técnico em Saneamento } \\
\text { /PROEJA, no IFBA, campus de } \\
\text { Salvador: um estudo de caso. }\end{array}$ & $\begin{array}{l}\text { IFBA - } \\
\text { Salvador }\end{array}$ & $\begin{array}{c}\text { Apenas os docentes foram sujeitos } \\
\text { da pesquisa }\end{array}$ \\
\hline E06 & 2014 & $\begin{array}{l}\text { VITORETTE, } \\
\text { Jacqueline } \\
\text { M. B. }\end{array}$ & $\begin{array}{l}\text { A não cnsolidação do PROEJA } \\
\text { como política Pública de Estado }\end{array}$ & $\begin{array}{c}\text { IF's } \\
\text { brasileiros } \\
\text { (inclui IFBA) }\end{array}$ & $\begin{array}{c}\text { Vagas são oferecidas, mas não } \\
\text { preenchidas, gerando, com isso, } \\
\text { um desperdício. (?) }\end{array}$ \\
\hline E07 & 2015 & $\begin{array}{c}\text { OLIVEIRA, } \\
\text { Grace Itana } \\
\text { Cruz de }\end{array}$ & \begin{tabular}{|c|} 
Pedagogia da alternância: a \\
permanência e o desemenho \\
escolar no curso técnico em \\
agropecuária, PROEJA, IF BAIANO \\
campus Santa Inês
\end{tabular} & $\begin{array}{l}\text { IFBaiano - } \\
\text { Sta. Inês }\end{array}$ & $\begin{array}{c}\text { O Campus Santa Inês promoveu } \\
\text { uma seleção diferenciada para o } \\
\text { PROEJA, pautando-se em aspectos } \\
\text { específicas da EJA, }\end{array}$ \\
\hline E08 & 2015 & $\begin{array}{l}\text { BORGES, } \\
\text { Ricardo } \\
\text { Henrique } \\
\text { de Jesus }\end{array}$ & $\begin{array}{c}\text { As práticas pefagógicas de } \\
\text { articulação com o mundo do } \\
\text { trabalho na Eucação de Jovens e } \\
\text { Adultos : experiências do PROEJA } \\
\text { no Centro Estadual de Educação } \\
\text { Profissional- CEEP Newton } \\
\text { Sucupira / Salvador- BA }\end{array}$ & $\begin{array}{l}\text { CEEP } \\
\text { NEWTON } \\
\text { SUCUPIRA / } \\
\text { SALVADOR }\end{array}$ & $\begin{array}{l}\text { A maioria dos quase cem por cento } \\
\text { aqui já possui nível médio, mas } \\
\text { teve que se submeter ao PROEJA } \\
\text { pra ter um curso técnico. }\end{array}$ \\
\hline E09 & 2016 & \begin{tabular}{|} 
FLORES, \\
Tânia M.D.
\end{tabular} & $\begin{array}{c}\text { Política Pública PROEJA no IFBA } \\
\text { Campus S. Amaro (BA): } \\
\text { (Des)caminhos e consequências }\end{array}$ & $\begin{array}{l}\text { IFBA - Santo } \\
\text { Amato }\end{array}$ & $\begin{array}{c}\text { O PROEJA atende a um público } \\
\text { distante daquele traçado pelo } \mathrm{DB} \\
\text { da política }\end{array}$ \\
\hline E10* & 2017 & $\begin{array}{l}\text { SILVA, } \\
\text { Suélen G. } \\
\text { Paixão da }\end{array}$ & $\begin{array}{l}\text { O LUGAR do PROEJA no IFBA } \\
\text { campus Santo Amaro: uma } \\
\text { análise a partir da percepção } \\
\text { docente }\end{array}$ & $\begin{array}{c}\text { IFBA - Santo } \\
\text { Amaro }\end{array}$ & $\begin{array}{c}\text { o desempenho do integrado na } \\
\text { modalidade PROEJA é inferior ao } \\
\text { do integrado na modalidade } \\
\text { "regular" }\end{array}$ \\
\hline
\end{tabular}




\section{DISCURSOS POLÍTICO-NORMATIVOS}

A Constituição Federal de 1988 reconhece a Educação de Jovens e Adultos como modalidade específica da educação básica no bojo das políticas educacionais brasileiras e, ainda, estabelece o direito à educação gratuita para todos, inclusive aos que a ela não tiveram acesso na idade própria, garantindo o ensino fundamental obrigatório e gratuito para todos. Todavia, a verdade é que tal garantia, porém, não se efetivou. A política Educacional universalista, supostamente para todos, não deu conta dos seus objetivos, do contrário, políticas educativas compensatórias não seriam necessárias.

Então, não obstante a promulgação da Constituição em 88, percebe-se, na década seguinte, um vazio no âmbito de políticas públicas com investimentos no campo educacional. De acordo com Frigotto (2002, p.59), no âmbito organizativo e institucional, a educação básica, de direito social de todos, já sob os princípios neoliberais, passa a, paulatinamente, ser transformada e tratada como um serviço prestado e adquirido no mercado ou na filantropia. O discurso constitucional da "educação como direito de todos os cidadãos e dever do Estado" se esvazia à medida que o Estado se omite dos seus deveres e delega a centralidade do "serviço" ao mercado.

No artigo 60 do Ato das Disposições Constitucionais Transitórias, há o compromisso de o Poder Público, no período de dez anos (1988 a 1998), desenvolver esforços para eliminar o analfabetismo e universalizar o ensino fundamental, com recursos previstos para esse fim. Entretanto, na reforma educacional brasileira da década de 90, optou-se por destinar os recursos públicos para o ensino fundamental de crianças e adolescentes, sob a alegação de que essa seria uma estratégia mais eficiente no sentido de prevenir o analfabetismo. (Di Pierro, 2010). A Educação, paradoxalmente, passa a ser direito de alguns. Aos brasileiros que compõem a EJA, excluídos do sistema educativo, restou a institucionalização da exclusão como meio de prevenção do analfabetismo, sob a lógica de que os jovens e adultos morrerão e, com eles, o analfabetismo.

Com a promulgação da Lei de Diretrizes e Bases da Educação Nacional (LDB 9.394/96), a EJA, com sua especificidade própria, é reconhecida como uma modalidade da educação básica nas etapas do ensino fundamental e médio, e sua oferta é regulamentada e assegurada a todos que não tiveram acesso ou condições de concluir os ciclos da educação básica em idade estabelecida por lei.

A LDB, que "Estabelece as diretrizes e bases da educação nacional", no Capítulo II, da Educação Básica, Seção V, Da Educação de Jovens e Adultos, em seu artigo 37, diz:

Art. 37. A educação de jovens e adultos será destinada àqueles que não tiveram acesso ou continuidade de estudos no ensino fundamental e médio na idade própria.

$\S 1$ O Os sistemas de ensino assegurarão gratuitamente aos jovens e aos adultos, que não puderam efetuar os estudos na idade regular, oportunidades educacionais apropriadas, consideradas as características do alunado, seus interesses, condições de vida e de trabalho, mediante cursos e exames. 
§ 2ㅇ O Poder Público viabilizará e estimulará o acesso e a permanência do trabalhador na escola, mediante ações integradas e complementares entre si. § 3으 A educação de jovens e adultos deverá articular-se, preferencialmente, com a educação profissional, na forma do regulamento. (Incluído pela Lei no 11.741, de 2008). (BRASIL, 1996)

Depreende-se, a partir deste ordenamento jurídico, que a EJA adquiriu maior abrangência e, ao menos em tese, passa a ser obrigatória e gratuita, do ponto de vista da oferta do estado, visto que a educação constitui-se num direito subjetivo. Outrossim, mais uma vez, no plano da ação, o discurso inclusivo e democrático da LDB, a garantia da oferta, da obrigatoriedade e gratuidade não se efetivaram. No quadro abaixo, é possível perceber que os indicadores nos dão conta de que o número de jovens e adultos fora do sistema escolar nos anos subsequentes, além de expressivos, são reveladores do distanciamento entre os discursos e a ação.

Tabela 1: distribuição dos estudantes de 18 a 24 anos de idade, segundo o nível frequentado no período de 1999 a 2009

\begin{tabular}{c|c|c}
\hline Nível de Ensino & $\mathbf{1 9 9 9}$ & $\mathbf{2 0 0 9}$ \\
\hline Ens. Fundamental & $24,8 \%$ & $8,3 \%$ \\
\hline Ens. Médio & $41,0 \%$ & $33,8 \%$ \\
\hline
\end{tabular}

Fonte: IBGE, 2010. Elaboração: Tânia Flores

Esse significativo decréscimo demonstra que não apenas não houve redução das desigualdades educacionais para o público da EJA, como também um alargamento no fosso da exclusão. A Constituição Federal e a LDB não foram suficientes para combater a exclusão e assegurar o respeito aos direitos dos cidadãos. A atuação dos Movimentos sociais foi preponderante e decisiva nesse momento, juntamente com a sociedade civil organizada, educadores, investigadores, estudiosos e teóricos, a exemplo de Paulo Freire, que ocuparam o espaço político, promoveram debates, Congressos, fóruns de discussões e reivindicações por políticas inclusivas para a EJA.

Em 2005, através do Decreto no 5.478/05, o governo institui o Programa de Integração da Educação Profissional ao Ensino Médio na Modalidade Educação de Jovens e Adultos, o PROEJA. Porém, este decreto foi substituído, no ano seguinte, pelo Decreto no 5.840 de 13 de julho de 2006, como forma de atender aos apelos e reivindicações do espaço político, efervescente naquele momento, por mudanças para a política, com a inclusão do ensino fundamental PROEJA-FIC ${ }^{2}$ - e a possibilidade de outras instituições serem proponentes, como os sistemas de ensino estaduais e municipais, entidades privadas nacionais de serviço social, aprendizagem e formação profissional, visto que, inicialmente, a oferta dos cursos coube unicamente aos Institutos Federais. A denominação passou a ser "Programa Nacional de Integração da Educação Profissional com a Educação Básica na Modalidade de Educação de Jovens e Adultos - PROEJA".

Segundo o DB do PROEJA (BRASIL, 2007), o principal objetivo da política é atender a demanda de jovens e adultos pela oferta de educação profissional técnica de nível médio, da qual, em geral, eram excluídos. O discurso veiculado em todo o documento, bem como nos demais ordenamentos que regulamentam a política, como a Resolução CNE/CEB ${ }^{3}$ № 1/2000 e o Parecer 
CNE/CEB no 11/2000, pauta-se, essencialmente, no compromisso de prover aos excluídos o direito a uma oportunidade real de inclusão tanto no sistema educativo, para elevação da escolaridade, como no mundo do trabalho, através de uma profissionalização.

O DB deixa a critério da instituição a oferta de vagas, formação de turmas e a forma como se dará a seleção dos candidatos, conforme se observa no item 5.5.

Oferta de vagas, inscrição, matrícula e organização de turmas": Os cursos deverão ser gratuitos e de acesso universal segundo os critérios do Programa. A instituição proponente se responsabilizará pela oferta de vagas, inscrição, matrícula e organização de turmas. As vagas deverão ser ofertadas na forma de edital público, podendo a seleção ser realizada por meio de processo seletivo simplificado, sorteio, entrevistas ou a combinação de vários instrumentos seletivos ou outros meios que a escola venha a adotar, considerando-se, imprescindivelmente, a condição de democratização do acesso. Os critérios para inscrição e matrícula dos interessados nos cursos e programas de educação profissional técnica de nível médio articulada ao ensino médio na modalidade EJA são: a) ter ensino fundamental concluído; b) ter idade compatível com a definida no projeto e em conformidade com a legislação sobre EJA (Parecer CNE/CEB no 11/2000 e Resolução CNE/CEB no 01/2000).) (grifo nosso) (BRASIL, 2007, p. 59)

Não cabe, portanto, qualquer dúvida quanto aos destinatários da política. Assim como não se pode desconhecer o processo histórico da luta da EJA por reconhecimento. Toda a legislação e regulamentações não deixam dúvidas de que o discurso que fundamenta e justifica o PROEJA é o da inclusão social, cujo objetivo é resgatar a enorme dívida social do Estado e da sociedade brasileira para com os jovens e adultos excluídos não só do acesso à educação, como também do mundo de trabalho em função do baixo nível de escolarização e da falta de qualificação profissional.

O discurso político-normativo pauta-se, portanto, na inclusão como instrumento para a transformação social, através de uma escola fundamentada na igualdade de oportunidades, a partir da afirmação do princípio da equidade na diferença, pois, "é preciso que tenhamos o direito de sermos diferentes quando a igualdade nos descaracteriza, e o direito de sermos iguais quando a diferença nos inferioriza" (Santos, 1995, p. 03). Assim, a inclusão é concebida como a reconstrução do vínculo social rompido, cuja consequência é a apartação social.

\section{PLANO DA AÇÃO: METANÁLISE DO CORPUS EMPÍRICO A PARTIR DA CATEGORIA DE ANÁLISE “ACESSO”}

Optou-se, nessa seção, por apresentar os estudos selecionados, conforme quadro abaixo, seguido de breve resumo do que foi analisado pelos autores. Para identificação dos estudos selecionados, adotaram-se códigos compostos a partir do número da investigação catalogada, presente na tabela 01, acrescido do ano de publicação. A exemplo, "E1-2010", para identificação do estudo "O PROEJA, seus beneficiários e as baixas taxas de conclusão em um dos cursos do programa". Assim, espera-se traçar um panorama que facilite a compreensão acerca do corpus teórico-empírico selecionado para metanálise neste artigo. 
Todos os estudos se inserem no paradigma qualitativo. A maioria alia também dados quantitativos na apreensão do real e interpretação da realidade estudada.

O E1- 2010 objetivou identificar os reais beneficiários do PROEJA e as razões das baixas taxas de conclusão dos estudantes. A investigação, de natureza mista, alia dados quali e quantitativos. A autora aborda a questão do acesso, das baixas taxas de conclusão e suas causas. O elevado número de disciplinas e a metodologia adotada pelos docentes são enfatizadas como fatores limitantes ao sucesso escolar, embora $71,4 \%$ dos beneficiários NÃO fossem público da EJA especificado pela política.

O E2-2011 investigou os percursos formativos dos sujeitos trabalhadores do PROEJA no IFBA, Campus Salvador. A investigadora parte da premissa de que os jovens e adultos, geralmente trabalhadores que retornam à escola em busca de profissionalização, trazem consigo significativas experiências, conhecimentos adquiridos pelo trabalho e, por isso, possuem estratégias próprias de aprendizagem e de resolução de problemas que podem funcionar como importantes recursos pedagógicos para uma educação inclusiva que propicie autonomia. Conclui, contudo, que a integração do currículo não contempla os percursos formativos dos estudantes-trabalhadores para além dos muros da escola. Embora o estudo não aborde direta e especificamente a questão do acesso, por meio das entrevistas com docentes e através das histórias de vida dos discentes, emergiu claramente o dado de que os ingressantes, conforme declara a Professora A, "Quem chega na nossa sala, a grande maioria já tem o ensino básico completo, então ele acaba vendo, repetindo, revendo os conteúdos e se distancia daquele perfil do público alvo que o Decreto almeja." (Almeida, 2011, p. 67), apesar de buscarem qualificação para melhorarem suas condições de vida.

O E3-2011, mais voltado para avaliação da efetividade e alcance da política no Instituto Federal de Educação, Ciência e Tecnologia da Bahia - IFBA, Campus Vitória da Conquista, buscou verificar se realmente ocorre a inclusão do público ao qual a política se destina. Para o investigador, o PROEJA, como política educativa compensatória, não encontrou ainda seu lugar na rede de escolas técnicas federais. Portanto, sua proposta de oferecer ao público da EJA, a formação profissional integrada ao ensino médio capaz de dar-lhes condições de melhoria de vida ainda não se consubstanciou, visto que $66 \%$ dos matriculados já concluíram o Ensino Médio, e o público da EJA permanece excluído em decorrência, especialmente, da ineficiência dessa política pública que se quer inclusiva.

O E4-2012, por meio de investigação de cunho qualitativo, pesquisa documental, aplicação de questionários semiestruturados aos docentes que atuaram no curso de 2009 a 2011 e entrevistas com os evadidos no interstício destes anos, o investigador aponta sérios desvios na execução da política no IFBaiano, Campus Guanambi, desde a carência de formação do corpo docente, passando pela organização do tempo e espaços de aprendizagens do estudantetrabalhador, até a comprovação de que a maioria do público que ingressa não apresenta o perfil pretendido pela política e, apesar disso, os índices de evasão são gritantes.

O E5-2014 teve como objetivo caracterizar as contradições da política, apresentada pelo Governo Federal como política pública educacional para a classe trabalhadora. Os 
resultados apontam contradições que vão desde a carência de preparação prévia, tanto humana quanto de estrutura e infraestrutura do IFBA, até a qualificação e formação docente para atuação nessa modalidade de ensino. A autora aponta como urgente a necessidade de um Projeto de Intervenção que redimensione o plano inicial contido no DB. Tais contradições, portanto, por si, já inviabilizam a inclusão pretendida pela política.

O E6-2014, uma tese cujo objetivo foi investigar o Proeja em cinco IFs (IFBA: 22 campi; IFES: 21 campi; IFG: 14 campi; IF-Farroupilha: 12 campi e IFSC com 22 campi), chama a atenção para o fato de que, não obstante o movimento contra-hegemônico nos IFs para a defesa da implantação do Proeja, ainda que a maioria das instituições e seus profissionais não tenham tido clareza sobre o que realmente é a política, o que se verifica é a concepção 'liberal de direitos iguais' que privilegia a meritocracia e desconsidera a diversidade, exclui os diferentes, os excluídos e desprivilegiados. Os principais resultados indicam, portanto, a não concretização do Proeja, que surgiu como política pública de governo, mas que se pretendia consolidar como política pública de Estado, conforme consta no DB (Brasil, 2007). Portanto, nos contextos da pesquisa, detectou-se que há oferta de vagas para o Proeja, mas essas não são preenchidas com candidatos almejados pela política, o que se deve, especialmente aos princípios meritocráticos no processo de seleção e falhas na divulgação da política e dos cursos, daí a incipiente procura pelo público da EJA.

O E6-2014 aborda importantes aspectos político-administrativos de grande relevância para o presente trabalho e, embora não apresente dados quantitativos quanto ao acesso, discursivamente, deixa claro que o público ingressante é, na sua maioria, distante daquele almejado pela política.

Já o E7-2015 revela-se, no bojo desta investigação, como a experiência mais exitosa do PROEJA nos IF's. O foco do estudo é apresentado a partir do entrelaçar dos caminhos da EJA, Educação Profissional e a Pedagogia da Alternância. Ao optar por essa pedagogia, o Instituto Federal Baiano - IFBaiano, Campus Santa Inês, assume uma perspectiva mais humanística da formação.

Ao considerar os modos de vida e condições existenciais dos sujeitos, o campus, através do curso Técnico em agropecuária-PROEJA, avança no sentido de garantir o acesso, a permanência e o desempenho escolar dos estudantes da EJA que vivem e trabalham no campo. Contudo, a oferta do curso na perspectiva da Pedagogia da Alternância, na prática, apresentou desafios e enfrentou diferentes formas de resistências. A influência da cultura escolar instituída ao longo da história da instituição foi uma das mais desafiadoras. Todavia, todos os estudantes atendem ao perfil traçado pela política e não houve evasão ou reprovação.

Neste ponto, é interessante ressaltar que os estudantes são de famílias de produtores rurais, majoritariamente pequenos agricultores da agricultura familiar. Nesse sentido, a Pedagogia da Alternância consiste em respeitar as condições de vida dos sujeitos, suas necessidades de trabalhar no campo, auxiliar a família com sua força de trabalho, mas também de estudar e se qualificar não só para a empregabilidade, mas para produzir mais e melhor.

Assim, os estudantes ficam alojados na instituição, em regime de internato, durante 15 dias, e participam das aulas teóricas e de laboratório, e durante os outros 15 dias, colocam em 
prática, em suas propriedades, o que aprenderam. Para tanto, contam com bolsa auxílio, transporte, alojamento, alimentação e monitores que vão ao campo supervisionar, avaliar e orientar as atividades. Não obstante os desafios enfrentados, essa foi a experiência mais exitosa da política no estado da Bahia.

O E8-2015 é a única investigação do corpus empírico analisado cujo locus não é um Instituto Federal, sim um Centro Estadual de Educação Profissional, situado no bairro Mussurunga, na cidade de Salvador. O objetivo da investigação foi levantar os possíveis fatores do êxito nos processos pedagógicos nos cursos de Eletromecânica e Eletrotécnica, ofertados pelo PROEJA

O autor identifica práticas que considera dinamizadoras do processo de ensino aprendizagem por conferirem atualização dos estudos, elevação da autoestima de seus sujeitos através da valorização das múltiplas inteligências, o que afirma ressignificarem a teoria e a prática profissional através da interdisciplinaridade e vivências concretas. Do ponto de vista do acesso, no entanto, evidenciou-se que $53 \%$ daqueles que frequentam já haviam concluído a Educação básica. A nível de análise da política pública, tal percentual denota preocupante desvio dos objetivos, embora o autor confirme que esses estudantes retornam à escola via Proeja em busca da qualificação profissional, uma vez que não conseguem aprovação nos cursos profissionalizantes na modalidade subsequente, direcionada para estudantes que já concluíram o ciclo da educação básica, porque a concorrência é alta, e a média, bastante elevada.

O E9-2016, de todo o corpus empírico aqui apresentado, é a única investigação que realiza uma avaliação ex post da política, ou avaliação de resultados, com o objetivo de averiguar se e em que medida a sua execução favorece a inclusão socioeducacional do público da EJA, bem como analisar as condições de acesso, permanência e conclusão dos estudantes do curso Técnico em Segurança do Trabalho, no IFBA, Campus Santo Amaro. A investigação alia dados qualitativos e quantitativos no intuito de apreender o real. Os resultados dão conta de que os editais do processo seletivo possibilitam o acesso por meritocracia, independente do perfil. No período de 2010 a 2014, no campus estudado, 89\% dos estudantes matriculados já haviam concluído a Educação Básica, dos quais, $6 \%$ com ensino superior completo ou interrompido. A autora conclui que o PROEJA finda por se constituir numa nova negação do direito à inclusão sócio-educacional dos sujeitos da EJA.

Por fim, o E10-2017 cujo objeto e locus da pesquisa foram os mesmos que o E09-2016, teve como objetivo analisar os significados dados ao PROEJA a partir da percepção dos docentes envolvidos. Embora a investigação não apresente dados quantitativos quanto à categoria acesso, dos discursos dos 24 docentes entrevistados, emergiu o dado, de que os discentes que compõem o Proeja no campus diferem do público alvo. De acordo com declarações dos dois coordenadores do curso durante o período de 2012 a 2016, "Com certeza mais de $90 \%$ de todo público que entra já tem EM completo." (Silva, 2017, p. 67). Ainda assim, os índices de evasão, segundo os entrevistados, são preocupantes e a política de permanência é bastante incipiente. 
Fica patente, portanto, em todos os estudos analisados - especialmente no E06-2014, que pesquisou a implantação e execução da política em 05 Institutos federais de diferentes estados brasileiros - que, na verdade, o PROEJA tem sido implantado como um programa, o que muito o fragiliza e permite distorções graves que mantêm a exclusão do público da EJA.

Tais distorções e fragilidades abordadas vão desde a implantação sem prévia infraestrutura como salas apropriadas, laboratórios e condições para aulas práticas, até a carência de formação obrigatória dos docentes, técnicos e gestores para atuação na execução da política, conforme determina o (DB, BRASIL, 2007), bem como o processo de seleção para o acesso do público que a política visa a incluir. O peso atribuído à redação (60\%) é, claramente, mais uma catraca sócioeducacional que um mecanismo de seleção para a inclusão.

A segregação e exclusão ficam muito claras ao analisarmos os dados. Apesar de tudo isso, os discursos institucionais responsabilizam o público da EJA por seu fracasso, por não aproveitar a oportunidade que lhe é oferecida. A tabela 3 evidencia e ilustra essa realidade.

Tabela 3: Perfil dos Ingressantes nos cursos do PROEJA

\begin{tabular}{c|c|c|c|c}
\hline \multirow{2}{*}{ ESTUDO / ANO } & \multicolumn{4}{|c}{ MATRICULADOS NO PROEJA } \\
\cline { 2 - 5 } & EJA & $\begin{array}{c}\text { EM } \\
\text { COMPLETO }\end{array}$ & $\begin{array}{c}\text { SUPERIOR } \\
\text { INC. }\end{array}$ & $\begin{array}{c}\text { SUPERIOR } \\
\text { COMP. }\end{array}$ \\
\hline E01 - 2010 & $28.6 \%$ & $67.5 \%$ & $2.6 \%$ & $1.3 \%$ \\
\hline E02 - 2011 & $25.0 \%$ & $75.00 \%$ & $0 \%$ & $0 \%$ \\
\hline E03 - 2011 & $34 \%$ & $66 \%$ & $0 \%$ & $0 \%$ \\
\hline E04 - 2012 & $40 \%$ & $60 \%$ & $0 \%$ & $0 \%$ \\
\hline E05 - 2014 & NA & NA & NA & NA \\
\hline E06 - 2014 & NA & NA & NA & NA \\
\hline E07 - 2015 & $100 \%$ & $0 \%$ & $0 \%$ & $0 \%$ \\
\hline E08 - 2015 & $47 \%$ & $53 \%$ & $0 \%$ & $6 \%$ \\
\hline E09 - 2016 & $11 \%$ & $83 \%$ & $0 \%$ & $6 \%$ \\
\hline E10 - 2017 & $11 \%$ & $83 \%$ & $0 \%$ & $1.66 \%$ \\
\hline Medias Ponderadas & $37.08 \%$ & $60.94 \%$ & $0.33 \%$ & \\
\hline
\end{tabular}

Fonte: elaboração Tânia Flores

Quanto à categoria acesso, os dados percentuais denotam a negação do direito à educação aos sujeitos da EJA, o que revela desvios dos objetivos da política. O público que efetivamente é 'aprovado' no processo seletivo é, majoritariamente, composto por estudantes que já concluiram o ciclo da educação básica e desenvolveram, portanto, as competências exigidas na redação ${ }^{2}$. Prevalece, assim, a meritocracia. O DB deixa claro que às instituições cabe definir as ofertas de vagas e meios de seleção, porém, "considerando-se, imprescindivelmente, a

\footnotetext{
${ }^{2}$ Vale ressaltar que, na Bahia, a partir de 2017, o IFBA eliminou a prova da redação. O IFBaiano, já realizava o processo seletivo com ênfase na entrevista realizada pelas pedagogas e assistentes sociais.
} 
condição de democratização do acesso" e "em conformidade com a legislação sobre EJA" (BRASIL, 2007, p.59, ) na prática, as instituições ignoram a legislação sobre a EJA.

O E05-2014 e o E06-2014, não apresentam dados percentuais sobre o acesso, mas sinalizam, conforme apresentado no resumo, que há desigualdades e concorrência entre desiguais nos processos seletivos, em que a maioria dos "aprovados" não possue distorção sérieidade. Já o E07-2015 é uma exceção e uma experiência pontual, visto que formou uma única turma. Portanto, os dados percentuais são maiores que os apresentados acima e, por isso mesmo, denotam a negação do direito à educação aos sujeitos da EJA, o que revela desvios dos objetivos da política.

A média ponderada do acesso do público da EJA nos cursos PROEJA no Estado da Bahia é de $37,08 \%$ contra $60,94 \%$ de estudantes que já concluíram a Educação Básica; 0,33\% com ensino superior incompleto e 1,66 com ensino superior completo. Esses dados trazem consigo todo um discurso de exclusão e manutenção das desigualdades travestido de promessa de inclusão.

Faz-se, a seguir, uma síntese, a partir dos estudos analisados, com os principais aspectos apontados como fragilidades, distorções, deficiências e fatores limitantes no que concerne à paradoxal negação do direito à inclusão, advinda do "modo de execução", ou plano da ação da política pública Proeja:

Percebe-se, a partir da análise dos dados, o que a literatura, notadamente Ranciére (2004) e Crouch $(2000,2004)$, identificam como sintomas da pós-democracia, ou seja, práticas que enfraquecem a democracia, "democraticamente". A política pública, nessa perspectiva, traduz-se como uma promessa de inclusão através da democratização do ensino; mas, na verdade, como resultado do seu modo de execução, esse fazer democrático consubstancia aquilo que Ranciére chamou de "la part des sans part", que pode ser traduzido como "a parte dos que não têm parte" ou "a parte que não faz parte".

Nesse sentido, Carrano (2013), questiona se

O que somos seria apenas uma questão de força de vontade? Esta é uma verdade relativa. As oportunidades objetivas de inserção e integração social são tão escassas em determinadas circunstâncias, que anulam, em última instância, o campo simbólico de autonomia de determinados sujeitos desigual e inferiormente posicionados na sociedade. (CARRANO, 2013, p.200)

No caso do Proeja, observa-se que a força de vontade para os candidatos com perfil traçado pela política não é o bastante para vencer do desafio o acesso. Segundo os estudos analisados, a meritocracia prevalece sobre o perfil dos excluídos. $O$ pretenso reconhecimento dos saberes e experiências de vida, tempos e modos de aprendizagem dessas pessoas não é levado em consideração no processo seletivo e, portanto, na execução da política. 
Tabela 4: Aspectos limitantes do Proeja

\begin{tabular}{|c|c|c|c|c|c|c|c|c|c|c|}
\hline \multirow{2}{*}{ FRAGILIDADES, DISTORÇÕES E FATORES LIMITANTES DO PROEJA } & \multicolumn{10}{|c|}{ ESTUDOS } \\
\hline & E1 & E2 & E3 & E4 & E5 & E6 & E7 & E8 & E9 & E10 \\
\hline \multicolumn{11}{|l|}{ a) Quanto ao aspecto da implantação e fragillidades do PROEJA: } \\
\hline Implantação por imposição do MEC & $\mathbf{x}$ & $\mathbf{x}$ & $x$ & $x$ & $\mathbf{x}$ & $\mathbf{x}$ & $\mathbf{X}$ & & $\mathbf{X}$ & $\mathbf{x}$ \\
\hline Ausência de diálogo com a comunidade interna e externa; & $\mathbf{x}$ & $\mathbf{x}$ & & $\mathbf{X}$ & $\mathbf{x}$ & $\mathbf{X}$ & & $\mathbf{X}$ & $\mathbf{X}$ & $\mathbf{x}$ \\
\hline SETEC/MEC não acompanharam/avaliaram a políitica & $\mathbf{x}$ & $x$ & $x$ & & & $x$ & & & $x$ & $\mathbf{x}$ \\
\hline $\begin{array}{l}\text { Desconhecimento da política e seus objetivos por parte da } \\
\text { instituição; }\end{array}$ & $x$ & $X$ & $x$ & $x$ & $x$ & $x$ & & $x$ & $x$ & $x$ \\
\hline Desconhecimento institucional sobre o público-alvo & $\mathbf{x}$ & $\mathbf{x}$ & $x$ & $x$ & $\mathbf{x}$ & $x$ & $\mathbf{X}$ & $\mathbf{X}$ & $\mathbf{x}$ & $\mathbf{x}$ \\
\hline $\begin{array}{l}\text { Maioria dos docentes do PROEJA desconhece as especificidades da } \\
\text { EJA. }\end{array}$ & $x$ & $X$ & $x$ & $x$ & $x$ & $x$ & $x$ & & $x$ & $x$ \\
\hline estrutura do curso/currículo enciclopédico & $\mathbf{x}$ & $\mathbf{x}$ & $x$ & & $\mathbf{X}$ & $\mathbf{X}$ & & $\mathbf{X}$ & $\mathbf{x}$ & $\mathbf{x}$ \\
\hline Não integração do curículo & $\mathbf{x}$ & $\mathbf{x}$ & $x$ & $x$ & $\mathbf{x}$ & $x$ & $\mathbf{x}$ & $\mathbf{x}$ & $\mathbf{x}$ & $x$ \\
\hline $\begin{array}{l}\text { Insuficiência/ausência de capacitação de docentes, técnicos e } \\
\text { gestores para EJA. }\end{array}$ & $x$ & $x$ & $x$ & $x$ & $X$ & $x$ & $x$ & $x$ & $x$ & $x$ \\
\hline altos índices de evasão & $\mathbf{X}$ & $\mathbf{x}$ & $x$ & $x$ & & & & $\mathbf{x}$ & $\mathbf{x}$ & $\mathbf{x}$ \\
\hline \multicolumn{11}{|l|}{ b) Quanto ao aspecto do acesso: } \\
\hline seleção meritocrática ( redação peso 6 eliminatória & $\mathbf{x}$ & $\mathbf{x}$ & & $x$ & & $x$ & & & $\mathbf{X}$ & $\mathbf{x}$ \\
\hline Divulgação não alcança público alvo & $\mathbf{X}$ & & $\mathrm{x}$ & $x$ & & $x$ & & & $\mathbf{x}$ & $\mathbf{x}$ \\
\hline Alegação institucional: o público alvo não se inscreve; & $\mathbf{x}$ & $\mathbf{x}$ & $x$ & $x$ & & $\mathbf{x}$ & & $\mathbf{X}$ & $\mathbf{x}$ & $\mathbf{x}$ \\
\hline $\begin{array}{l}\text { Acesso majoritário de candidatos com EM completo ou superior } \\
\text { (in)completo }\end{array}$ & $x$ & $X$ & $x$ & $x$ & & $x$ & & $x$ & $\mathbf{x}$ & $x$ \\
\hline discriminação do PROEJA na instituição & $\mathbf{x}$ & $x$ & & & & $x$ & $\mathbf{x}$ & & $\mathbf{X}$ & $\mathbf{x}$ \\
\hline
\end{tabular}

Elaboração: Tânia Flores

Importante destacar que o insucesso da política decorre, sobretudo, da discrepância entre os discursos políticos-normativos - declaração das intenções - e a materialidade do Proeja - seu modo de execução - fruto do (des)compromisso do estado e das instituições de ensino que a executam. O E07-2015, intitulado "Pedagogia da alternância: a permanência e o desempenho escolar no curso técnico em agropecuária, PROEJA, IF BAIANO campus Santa Inês" é forte exemplo de que, apesar dos desafios, a inclusão preconizada pela política é possível quando existe vontade política e ação conjunta e coerente na sua execução. Essa foi uma experiência exitosa em vários aspectos mas, na Bahia, uma ação isolada.

\section{CONSIDERAÇÕES FINAIS}

O Proeja é, no plano do discurso político-normativo, uma política pública inclusiva. No plano da ação, todavia, cada campus dos Institutos Federais e outras Unidades das Escolas Estaduais concebem-na e a implantam mais como um programa, como tantos outros que surgem, 
bem ao gosto da pós-democracia, mais para esvaziar o espaço político e promover a despolitização e desmobilização da sociedade, através de medidas e/ou políticas que supostamente atendam às suas reivindicações. Mal concebidos e precariamente executados, logo são sucedidos por outros de nomenclaturas fortes, mas com desenho e execução semelhantes aos antecedentes, porém, agregando outros pontos reivindicados por segmentos e setores da sociedade. Desse modo, o estado politicamente dá uma resposta à sociedade. Tal resposta, porém, repousa sobre a superfície do espaço político, ao nivel do discurso, das aparências e das plataformas eleitorais. Ao nível subjacente, da ação, da execução do planejamento, predomina o laissez faire, o descompromisso com os objetivos estabelecidos, o espontaneísmo no modo de execução da política, a ausência de monitoramento e avaliação dos processos. Ao fim e ao cabo, parece existir mesmo, se não um esforço, mas um movimento contrário ao compromisso assumido. Evidencia-se, então, uma clara alteração discursiva entre a demanda social, a formulação da política pública Proeja e a sua efetiva execução.

O estado esteve presente na indução do Proeja através de financiamento específico para formação de professor, de gestor e de técnico administrativo, bem como de destinação de recursos para implantação e execução da política e criação de legislação e regulamentações apropriadas para nortear os gestores das instituições proponentes. Entretanto, o mesmo estado ausentou-se e eximiu-se do compromisso de acompanhar, monitorar e avaliar a implantação, execução e resultados dessa política de tamanha relevância social.

No período estudado, 2010 a 2017, conforme dados apresentados, verificam-se distorções, desvios, falhas técnicas e metodológicas no modo de execução do Proeja e, segundo afirma Flores (2016, p. 117), através de email, em maio de 2015, a equipe PROEJA/SETEC/MEC informou: "(...) de acordo com a área técnica consultada, não possuímos dados sobre o PROEJA". A política foi criada inicialmente em 2005. Portanto, a SETEC/MEC admitem que, em 10 anos de execução, a política não foi avaliada. Ora, de acordo com Saravia e Ferrarezi (2006, p. 32), a execução é o conjunto de ações destinadas a atingir os objetivos estabelecidos para uma determinada política; por isso necessita de acompanhamento, ou seja, supervisão sistemática da execução; e, por fim, a avaliação, que consiste na análise dos resultados a fim de verificar se os objetivos foram atendidos e também subsidiar os atores no sentido de traçar novas estratégias para corrigir desvios ou equívocos. Portanto, os objetivos que justificam a sua criação não foram norteadores da ação, e a política tem cumprido, a contento, sua função social da inclusão dos efetivamente excluídos do direito à educação.

O acesso ao Proeja, portanto, deve basear-se na clara compreensão da modalidade de ensino, em conformidade com a legislação sobre EJA (Parecer CNE/CEB no 11/2000 e Resolução CNE/CEB no 01/2000). Logo, toda e qualquer política que seja pautada no discurso político da inclusão, especialmente na área da educação, e notadamente para os sujeitos da EJA, exige uma implementação planejada com vistas a oferecer condições favoráveis para que sua execução - Plano da ação - seja a partir do pensamento da diversidade para que, de fato, se efetive o direito à educação, mediante uma coerente política de acesso, importante passo na operacionalização do planejamento. 
Os dados indicam inequivocamente que, entre o plano dos discursos e o plano da ação, existe um abismo cujas causas parecem ser o descompromisso, a falta de vontade política do estado e dos demais agentes responsáveis pela execução da política pública Proeja. A inclusão pretendida finda por ser uma exclusão ainda mais cruel que aquela que a política se propõe a combater. E a escola permanece como um não-lugar para os excluídos; e o espaço político, como espaço ausente, visto que as vozes foram silenciadas pela utopia da inclusão.

Desse modo, o grande contributo da presente investigação é instigar outros investigadores a fim de que o MEC corrija os desvios da política e a redirecione no sentido de cumprir os objetivos traçados e promover a inclusão anunciada.

\section{REFERÊNCIAS BIBLIOGRÁFICAS}

Almeida, Márcia Simões de. (2011). Da formação do sujeito ao sujeito da formação: saberes e experiências dos jovens e adultos do PROEJA. Recuperado de: https://sistema.bibliotecasbdigital.fgv.br/bases/portal-dominio-publico-teses-e-dissertacoes-capes

Arendt, H. (1993). O interesse pela política no recente pensamento filosófico europeu. In A dignidade da Política. Rio de Janeiro: Relume-Dumará.

Bogdan, Roberto C.; Biklen, Sari Knopp. (1994). Investigação qualitativa em educação. Tradução Maria João Alvarez, Sara Bahia dos Santos e Telmo Mourinho Baptista. Porto: Porto Editora.

Bonfim, Silvana V. M. da Silva. (2012). A problemática da evasão dos estudantes vinculados ao PROEJA no IF BAIANO - Campus Guanambi. Recuperado de: https://sistema.bibliotecasbdigital.fgv.br/bases/portal-dominio-publico-teses-e-dissertacoes-capes

Borges, Ricardo Henrique de Jesus. (2015). As práticas pefagógicas de articulação com o mundo do trabalho na Eucação de Jovens e Adultos : experiências do PROEJA no Centro Estadual de Educação Profissional- CEEP Newton Sucupira / Salvador- BA. Recuperado de: https://sistema.bibliotecas-bdigital.fgv.br/bases/portal-dominio-publico-teses-edissertacoes-capes

Brasil, (1996). Lei de Diretrizes e bases da Educação Nacional. № 9.394 de dezembro. Recuperado de: < http://portal.mec.gov.br/seesp/arquivos/pdf/lei9394 Idbn1.pdf>

Brasil. (2000). Ministério da Educação. Conselho Nacional de Educação. Parecer CEB 11/2000. Institui as Diretrizes Curriculares Nacionais sobre a Educação de Jovens e Adultos.

Brasil. (2000). RESOLUÇÃO CNE/CEB № 1, DE 5 DE JULHO. Recuperado de: http://confinteabrasilmais6.mec.gov.br/images/documentos/resolucao_CNE_CEB_0

1_2000.pdf acesso em agosto/18

Brasil. (2007). Secretaria de Educação Profissional e Tecnológica. Programa de Integração da Educação Profissional Técnica de Nível Médio ao Ensino Médio, na Modalidade de Educação de Jovens e Adultos - PROEJA. Documento Base. 
Bryman, A. (2012). Social Research Methods (4 ed.) New York: Oxford University Press.

CAPES - Coordenação de Aperfeiçoamento de Pessoal de Nível Superior. Banco de teses e dissertações. https://sistema.bibliotecas-bdigital.fgv.br/bases/portal-dominio-publico-tesese-dissertacoes-capes

Cardoso, T. M. L. (2007). Interação verbal em aulas de línguas: meta-análise da investigação portuguesa entre 1982 a 2002. Tese. Universidade de Aveiro. Portugal.

Carrano, Paulo. (2013) Identidades culturais juvenis e escolas: arenas de conflitos e possibilidades. In Moreira, A. F. \& Candau, V. M. (Orgs.). Multiculturalismo: diferenças culturais e práticas pedagógicas. 10. ed. Petrópolis, RJ: Vozes.

Coutinho, C. P. (2016). Metodologias de Investigação em Ciências Sociais e Humanas: Teoria e Prática (2nd ed.). Coimbra: Edições Almedina.

Crouch, c. (2000). Coping with Post-Democracy. Cambridge: Fabian Society

Crouch, C. (2004). Post-Democracy. Oxford, United Kingdom: Polity Press.

Di Pierro, M. C. (2010). A Educação de Jovens e Adultos no Plano Nacional de Educação: Avaliação, desafios e perspectivas. Educação\& Sociedade, Campinas, 31(112), 939-959. Recuperado de: http://www.scielo.br/pdf/es/v31n112/15.pdf

Fernandes, Marta Quadros. (2011). O Instituto Federal de Educação, Ciência e Tecnologia da Bahia e o PROEJA: $O$ caso do Campus de Vitória da Conquista. Recuperado de: https://sistema.bibliotecas-bdigital.fgv.br/bases/portal-dominio-publico-teses-edissertacoes-capes

Finfgeld, D.L. (2003). Metasynthesis: O estado da arte - até agora. Pesquisa Qualitativa da Saúde, 13: 893 - 904 .[Crossref] , [PubMed] , [Web of Science ${ }^{\circledR}$ ],[Google Scholar]

Flores, Tânia M.D. (2016). Política Pública PROEJA no IFBA Campus S. Amaro (BA): (Des)caminhos $e$ consequências. Recuperado de: https://sistema.bibliotecas-bdigital.fgv.br/bases/portaldominio-publico-teses-e-dissertacoes-capes

Frigotto, Gaudêncio. (2002) Educação e a construção democrática no Brasil: da ditadura civil/militar à ditadura do capital. In Democracia e Construção do Público no pensamento educacional brasileiro. Petrópolis: Vozes.

Healey, P. (2006). Relational complexity and the imaginative power of strategic spatial planning.

http://dx.doi.org/10.7867/1809-0354.2013v8n3p1033-1048.

IBGE - Instituto Brasileiro de Geografia e Estatística, 2010. http://www.ibge.gov.br

Lima, Jacilene Fiúza de. (2010). O PROEJA, seus beneficiários e as baixas taxas de conclusão em um dos cursos do Programa. Recuperado de: https://sistema.bibliotecasbdigital.fgv.br/bases/portal-dominio-publico-teses-e-dissertacoes-capes 
Lopes, A. L. M.; Fracolli, L. A. (2008). Revisão sistemática de literatura e metassíntese qualitativa: considerações sobre sua aplicação na pesquisa em enfermagem. Texto, Contexto, Enfermagem. Florianópolis, out-dez, p. 771-778. Minesota Press.

Oliveira, Grace Itana Cruz de. (2015). Pedagogia da alternância: a permanência e o desemenho escolar no curso técnico em agropecuária, PROEJA, IF BAIANO campus Santa Inês. Recuperado de: $\quad$ https://sistema.bibliotecas-bdigital.fgv.br/bases/portal-dominio-publico-teses-edissertacoes-capes

Oliveira, Maria da C. da V. P. de. (2014). O curso Técnico em Saneamento/PROEJA, no IFBA, campus de Salvador: um estudo de caso. Recuperado de: https://sistema.bibliotecasbdigital.fgv.br/bases/portal-dominio-publico-teses-e-dissertacoes-capes

Pinto, Cândida Martins. (2013) Metanálise Qualitativa Como Abordagem Metodológica para Pesquisas m Letras. Atos de Pesquisa em Educação 8(3) 1033-1048, set./dez. 2013 DOI. Recuperado de: http://dx.doi.org/10.7867/1809-0354.2013v8n3p1033-1048

Rancière, J. (1999). Disagreement: politics and philosophy (Rose, tran). Minneapolis: University of University of Minesota Press.

Rancière, J. (2014). O ódio à democracia. (1a ed.) Tradução de Mariana Echalar. São Paulo: Boitempo.

Ribeiro, M. (2006). Exclusão e educação social: conceitos em superfície e fundo. Educação \& Sociedade, 27(94), 155-178. https://dx.doi.org/10.1590/S0101-73302006000100008

Santos, B. de S.. Entrevista com Prof. Boaventura de Souza Santos.

Saravia, E.; Ferrarezi, E. (orgs.). (2006). Políticas públicas. V I. Brasília: ENAP.

Silva, S G. P. da. (2017). O Lugar do PROEJA no IFBA campus Santo Amaro: uma análise a partir da percepção docente. Recuperado de: https://sistema.bibliotecas-bdigital.fgv.br/bases/portaldominio-publico-teses-e-dissertacoes-capes

Vitorette, Jacqueline M. B. (2014). A não cnsolidação do PROEJA como política Pública de Estado. Recuperado de: https://sistema.bibliotecas-bdigital.fgv.br/bases/portal-dominio-publicoteses-e-dissertacoes-capes

Zimmer, L. (2004). Qualitative meta-synthesis: a question of dialoguing with texts. J. Adv. Nurs. Fev; p. 311-318. Recuperado de: https://www.ncbi.nlm.nih.gov/pubmed/16441536 acesso: 02/06/18.

\section{COMO CITAR ESTE ARTIGO:}

Flores, T. M. D. (2020). Política pública educativa Proeja: entre o plano dos discursos e o plano da ação no contexto do neoliberalismo. 36(6), 1-20

SOBRE OS AUTORES 


\section{T. M. D. FLORES}

Docente de Língua Portuguesa, Literatura e Redação do IFBA - Campus Santo Amaro; Especialista em Metodologia do Ensino de Língua Portuguesa e Literaturas; Mestre em educação, pela Universidade Federal de Sergipe-UFS- doutoranda em Educação pela Universidade de Aveiro-Portugal.

E-mail: taniaflores@ifba.edu.br

ORCID ID: http://orcid.org/0000-0001-7580-6234

Editor(a) Responsável: Francinaide de Lima Silva Nascimento

Pareceristas Ad Hoc: Mylenna Cacho e Antonio Uchoa

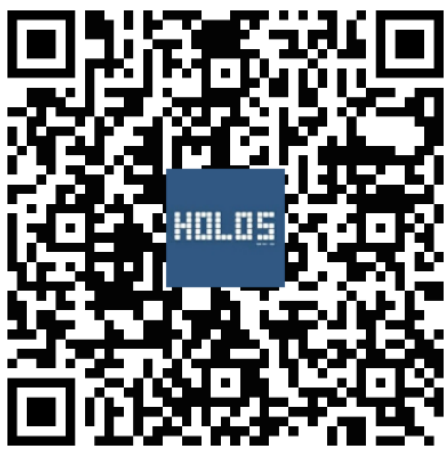

